\title{
Avaliação agronômica de biossólidos tratados por diferentes métodos químicos para aplicação na cultura do milho
}

\author{
Ivaldete T. Barros ${ }^{1}$, Cleverson V. Andreoli ${ }^{2}$, Ivan G. de Souza Junior ${ }^{3}$ \& Antonio C. S. da Costa ${ }^{3}$ \\ RESUMO \\ A presença de patógenos e metais potencialmente tóxicos, são as principais limitações do lodo de \\ esgoto para a reciclagem agrícola. Este trabalho avaliou a aplicação de biossólidos, tratados quimicamente, \\ em um Latossolo Vermelho distrófico, na produção de matéria seca e na absorção de nutrientes pela \\ cultura de milho. O lodo de esgoto foi tratado com cal, hipoclorito de sódio, peróxido de hidrogênio, \\ ácido acético e peracético. N os biossólidos tratados com os ácidos orgânicos fez-se a neutralização com \\ cal. O s biossólidos foram aplicados em vasos, na dose de 50 t ha-1 cultivado com milho pelo período de \\ 55 dias, quando foram determinadas a produção de matéria seca e concentração de nutrientes na parte \\ aérea das plantas. A maior produção de matéria seca foi observada no tratamento com ácido peracético \\ e a menor no tratamento com cal. A aplicação de biossólido aumentou os teores dos macronutrientes na \\ parte aérea das plantas. $\mathrm{O} s$ teores de $\mathrm{Zn}, \mathrm{Cu}, \mathrm{Mn}, \mathrm{Fe}$ e $\mathrm{Pb}$ nas plantas, estiveram abaixo dos limites \\ fitotóxicos. O s biossólidos mostraram ser uma importante fonte de nutrientes para o desenvolvimento \\ da cultura de milho. Os tratamentos alternativos do lodo podem ser eficientes no controle de patógenos \\ e facilitam a reciclagem agrícola de biossólidos.
}

Palavras-chave: lodo de esgoto, produção vegetal, reciclagem agrícola

\section{Agronomic evaluation of biosolids treated by different chemical methods for cultivation of maize}

\begin{abstract}
The presence of pathogens and potentially toxic metals are the main limitations for the agronomic recycling of sewage sludge. This study evaluated the application of biosolids, chemically treated in a distrophic Red Latosol in the production and in the absorption of nutrients by the maize crop. The sludge was treated with lime, sodium hypochlorite, hydrogen peroxide, peracetic and acetic acids. Biosolids treated with organic acids were neutralized with lime. The biosolids were applied in pots at a dose equivalent to $50 \mathrm{t} \mathrm{ha}^{-1}$ and maize was grown for a period of 55 days, and later the dry matter production and concentrations of nutrients were determined in the shoots. The highest dry matter production was observed in treatment with peracetic acid (APA) and the lowest in the treatment with lime. The application of biosolids increased the levels of macronutrients in the plant shoots. The concentration levels of $\mathrm{Zn}, \mathrm{Cu}, \mathrm{Mn}, \mathrm{Fe}$ and $\mathrm{Pb}$ in the plants were below the phytotoxic limits. The biosolids showed to be an important source of nutrients for the initial development of the maize crop. Alternative treatments of the sludge can be effective in controlling pathogens and facilitate agricultural recycling of biosolids.
\end{abstract}

Key words: sewage sludge, vegetal production, agricultural recycling 


\section{INTRODUÇÃO}

A contaminação de corpos hídricos com matéria orgânica tem origem principalmente nos esgotos domésticos e em águas residuárias das agroindústrias (Pedroza et al., 2006). A construção de Estações de Tratamento de Esgoto (ETE) é uma das etapas importantes para a solução da destinação do esgoto mas na sua operação são gerados alguns resíduos um dos quais denominado lodo de esgoto, que necessita de tratamento e disposição final adequada (Martins et al., 2003).

Dentre as diversas alternativas de destinação final para o lodo de esgoto, a forma predominante no mundoé a reciclagem agrícola, recomendada pela Agenda 21; no entanto, essa disposição exige que o lodo apresente características químicas e biológicas que garantam a segurança ambiental e sanitária. $\mathrm{O}$ lodo de esgoto, quando apresenta essas características, é denominado biossólido (Andreoli et al., 2001b).

O uso do biossólido é a alternativa mais viável e interessante, pois é fonte de matéria orgânica e de nutrientes para as plantas (Ros et al., 1991) e, quando tratado com cal, age como corretivo da acidez do solo (Berton et al., 1989), além de proporcionar benefícios na fertilidade do solo (Melo et al., 2001) e a produção agrícola (Nascimento et al., 2004) com a elevação do $\mathrm{pH}$ e do poder tampão, redução da acidez trocável, aumento na disponibilidade de nutrientes (Vieira \& Cardoso, 2003), melhoria da capacidade de troca catiônica e no estímulo à atividade microbiana do solo (Andreoli et al., 2001a).

Além disso, a adição de matéria orgânica melhora os atributos físicos do solo, agindo como agente cimentante, favorecendo a agregação de suas partículas, reduzindo sua coesão e plasticidade e melhorando sua capacidade de retenção de água (Andreoli et al., 2001a). A matéria orgânica e os cátions presentes $\left(\mathrm{Ca}^{2+} \mathrm{e}^{3+}\right.$ dentre outros) determinam, ao promover a agregação de partículas do solo, aumento no seu volume, causando redução na sua densidade como consequência do aumento do índice de vazios (Melo et al., 2001).

Para que o biossólido não cause problemas ambientais e de saúde pública, é necessário que seja tratado (Rocha \& Shirota, 1999), visando à redução e/ou à eliminação de odores desagradáveis, micro-organismos patogênicos, elementos tóxicos e dificuldades de desidratação (Pedroza et al., 2003). A presença de micro-organismos patogênicos (Lopes et al., 2005) e metais potencialmente tóxicos (Rao \& Shantaran, 1996) são as principais limitações à reciclagem agrícola dos biossólidos.

Os principais patógenos encontrados no lodo são: ovos de helmintos, cistos de protozoários, bactérias e vírus entéricos (Lopes et al., 2005). A concentração desses patógenos é dependente da origem, da época do ano e do processo de tratamento do biossólido que podem ser físicos, biológicos e químicos. Os tratamentos mais utilizados são: digestão aeróbia e anaeróbia, compostagem e calagem (Thomaz-Soccol et al., 1998).

Um método alternativo para a desinfecção de lodo de esgoto utiliza ácidos orgânicos que apresentam vantagens potenciais contra outros desinfetantes químicos, como a falta de efeitos adversos no ambiente receptor e a rápida evolução para uma biodegradação inócua e fácil (Sánchez-Ruiz et al., 1995). Essas características são de grande importância para a sustentabilidade do sistema agrícola produtivo, visto que minimizam o impacto ambiental da aplicação do biossólido na reciclagem agrícola.

Os ácidos orgânicos: acético $\left(\mathrm{C}_{2} \mathrm{H}_{4} \mathrm{O}_{3}\right)$ e peracético $\left(\mathrm{CH}_{3} \mathrm{COOOH}\right)$ utilizados na higienização de lodo de esgoto apresentaram efeito muito bom contra bactérias, vírus, cistos de protozoários e ovos de helmintos, sob diversas condições (Fraser et al., 1984; Sánchez-Ruiz et al., 1995; Barrios et al., 2002; Gonzáles et al., 2002).

Embora o mecanismo de desinfecção dos ácidos orgânicos não seja ainda bem entendido, sabe-se que os ácidos agem significativamente, destruindo bactérias e ovos de helmintos que são altamente resistentes aos tratamentos convencionais (Barros et al., 2006). Outro ponto positivo da utilização dos ácidos orgânicos é o curto período de tempo de contato necessário do ácido, 10 a 30 min, para inativação dos agentes patogênicos (Barrios et al., 2002). No caso da utilização da cal são necessárias várias semanas para a maturação dos biossólidos e morte dos micro-organismos (Thomaz-Soccol et al., 1998), porém os produtos químicos utilizados podem alterar as características químicas do lodo, favorecendo ou não a disponibilidade dos nutrientes presentes.

A acumulação de metais potencialmente tóxicos nas plantas pode ocorrer sem que haja manifestação de sintomas de toxicidade e prejuízo na produção das culturas (Rao \& Shantaran, 1996). Esses elementos afetam os micro-organismos do solo (Valsecchi et al., 1995) e a qualidade dos alimentos (Soares et al., 2002); portanto, conhecer o destino desses elementos é essencial para a avaliação do impacto ambiental provocado pelo uso do lodo de esgoto no solo (Nogueira et al., 2007).

Este trabalho foi realizado com o objetivo de investigar o efeito do lodo de esgoto tratado com diferentes produtos químicos, quando de sua incorporação no solo como fonte de nutrientes para as plantas, de forma a avaliar sua influência no desenvolvimento da cultura de milho em vasos e a concentração dos elementos: N, P, K, Ca, Mg, Cu, Fe, Mn, Zn, Pb, Na, Cd, Cr e $\mathrm{Ni}$, na parte área das plantas.

\section{Material e MÉTOdos}

\section{Caracterização do solo}

O solo utilizado foi coletado na profundidade de $0-20 \mathrm{~cm}$, sendo este derivado do Arenito Caiuá e classificado como Latossolo Vermelho distrófico, de acordo com o Serviço Nacional de Levantamento e Conservação de Solos (EMBRAPA, 2006).

\section{Caracterização e tratamento químico do biossólido}

O biossólido utilizado no experimento é proveniente de tratamento biológico contendo um reator do tipo UASB (Upflow Anaerobic Sludge Blanket), que recebe e trata esgoto essencialmente doméstico, pelo processo anaeróbio. Os tratamentos avaliados com a finalidade de eliminar ou reduzir os patógenos, foram: o convencional, com a cal virgem dolomítica $(\mathrm{CaO} / \mathrm{MgO})$ com óxido de cálcio entre 65 e $58 \%$ do 
óxido total presente, e os considerados alternativos, utilizandose os ácidos orgânicos: acético $\left(\mathrm{C}_{2} \mathrm{H}_{4} \mathrm{O}_{3}\right)$ e peracético $\left(\mathrm{CH}_{3} \mathrm{COOOH}\right)$, hipoclorito de sódio $(\mathrm{NaClO})$ e peróxido de hidrogênio $\left(\mathrm{H}_{2} \mathrm{O}_{2}\right)$.

Para a caleação foi utilizada cal virgem dolomítica, no lodo de esgoto anaeróbio semidrenado com $33 \%$ de umidade. A caleação foi efetuada 120 dias antes da aplicação do lodo ao solo; após este período o lodo caleado foi secado ao ar e peneirado para incorporação ao solo, em proporção ao teor de sólidos do lodo.

Os demais tratamentos receberam os produtos químicos no lodo líquido, 98\% de umidade, a temperatura ambiente e submetidos a um tempo de contato de $30 \mathrm{~min}$.

Para determinação das doses dos produtos químicos utilizados na higienização do lodo, levaram-se em consideração trabalhos publicados por Fraser et al. (1984), Sánchez-Ruiz et al. (1995), Barrios et al. (2002), Gonzáles et al. (2002) e Andreoli et al. (2001b).

$\mathrm{O}$ experimento se constituiu de um delineamento inteiramente casualizado - DIC, com 13 tratamentos (Tabela 1) e 5 repetições, somando 65 vasos, que foram dispostos aleatoriamente em bancadas, na estufa do Laboratório de Caracterização e Reciclagem de Resíduos (LCRR) da Universidade Estadual de Maringá (UEM). Ao solo foram incorporados $25 \mathrm{~g}$ de lodo de esgoto seco por $\mathrm{kg}$ de solo, correspondente a $50 \mathrm{t} \mathrm{ha}^{-1}, 15$ dias antes da introdução da cultura.

O lodo de esgoto anaeróbio após higienização com os ácidos orgânicos (acético ou peracético) apresentava pH entre 4,2 e 6,1 , o qual foi parcialmente desidratado em leito de secagem, até alcançar um teor de sólido total próximo de $15 \%$. Procedeuse, então, à neutralização, para elevar o pH próximo à neutralidade; para tal, foram separadas amostras dos vários tratamentos do lodo, aos quais foram aplicadas diferentes doses de cal virgem dolomítica; após a determinação da dose de cal necessária para a neutralização de cada tratamento, a cal foi aplicada ao lodo, levando-se em consideração seu teor de sólidos totais e em comparação com o teor de sólido da amostra de determinação (Tabela 2); em seguida, a incorporação da cal ao lodo foi permitida a estabilização do $\mathrm{pH}$ em virtude das reações de neutralização, durante cinco dias.
Tabela 2. Características de cada tratamento que recebeu doses de cal para neutralização do lodo

\begin{tabular}{lcccc}
\hline Tratamento & $\begin{array}{c}\text { pH inicial } \\
\text { do lodo }\end{array}$ & $\begin{array}{c}\text { Doses de cal } \\
\text { CaO/Mg0 g } \\
\mathbf{1 0 0}^{-1} \mathbf{~ d e ~ l o d o ~}\end{array}$ & $\begin{array}{c}\text { Cal } \\
\%\end{array}$ & $\begin{array}{c}\text { pH final } \\
\text { do lodo }\end{array}$ \\
APA-05 & 6,1 & 0,02 & 0,32 & 6,5 \\
APA-10 & 4,8 & 0,20 & 2,90 & 6,5 \\
APA-20 & 4,4 & 0,40 & 6,45 & 6,7 \\
AA-22 & 4,2 & 0,60 & 16,70 & 6,5 \\
\hline
\end{tabular}

Produção de matéria seca e análise elemental da parte aérea da cultura de milho

Selecionou-se a cultura de milho (Zea mays L.) como indicadora, utilizou-se o híbrido Agroceres AG405, e se mantiveram cinco plantas por vaso, em todos os tratamentos. $\mathrm{O}$ experimento foi conduzido até 55 dias após semeadura, quando se coletaram as plantas, que foram cortadas rente ao solo para determinação de matéria seca da parte aérea (MSPA) e total (MST).

Para as determinações dos teores foliares de elementos químicos, as amostras de folhas da parte aérea das plantas (colmos + folhas) foram secadas e trituradas. No material seco e triturado procedeu-se à preparação dos extratos pela abertura das amostras por via úmida, através de digestão sulfúrica para a determinação de $\mathrm{N}$, e digestão nítrico perclórica para a determinação de $\mathrm{P}, \mathrm{K}$, $\mathrm{Ca}, \mathrm{Mg}, \mathrm{Cu}, \mathrm{Fe}, \mathrm{Mn}, \mathrm{Zn}, \mathrm{Pb}, \mathrm{Na}, \mathrm{Cd}, \mathrm{Cr}$ e Ni.

Todos os resultados obtidos para as variáveis analisadas dos diferentes materiais foram submetidos à análise de variância, através da análise de regressão, utilizando-se as rotinas do software SAS, no nível de $1 \%$.

Sempre que o teste F detectou diferença significativa entre tratamentos para as variáveis, procedeu-se ao desdobramento dos graus de liberdade em contrastes ortogonais. Para o fator tratamento, sempre que foi detectada diferença significativa também se procedeu ao detalhamento da análise através do teste de agrupamento Scott-Knott, considerando-se 5\% como nível mínimo de significância (Scott \& Knott, 1974).

\section{RESULTADOS E DISCUSSÃO}

\section{Produção de matéria seca}

A aplicação de biossólido promoveu aumento na quantidade de matéria seca das plantas de milho. A produção de massa

Tabela 1. D oses de produtos químicos aplicados na higienização e neutral ização do biossólido incorporado ao solo para a cultura de milho (Zea mays L.)

\begin{tabular}{|c|c|c|}
\hline Tratamento & Produto aplicado & Dose \\
\hline TEST-N & Solo natural & - \\
\hline TEST-A & Solo + biossólido & - \\
\hline CAL & Solo + biossólido caleado ( $\mathrm{CaO} / \mathrm{MgO})$ & $30 \%$ MS do lodo \\
\hline APA5N & Solo + biossólido tratado com ácido peracético & $230 \mathrm{mg} \mathrm{L}^{-1}$ \\
\hline APA5C & Solo + biossólido tratado com ácido peracético e cal & $230 \mathrm{mg} \mathrm{L}^{-1}, 0,32 \% \mathrm{cal}$ \\
\hline APA10N & Solo + biossólido tratado com ácido peracético & $460 \mathrm{mg} \mathrm{L}^{-1}$ \\
\hline APA10C & Solo + biossólido tratado com ácido peracético e cal & $460 \mathrm{mg} \mathrm{L}^{-1}, 2,9 \% \mathrm{cal}$ \\
\hline APA20N & Solo + biossólido tratado com ácido peracético & $920 \mathrm{mg} \mathrm{L}^{-1}$ \\
\hline APA20C & Solo + biossólido tratado com ácido peracético e cal & $920 \mathrm{mg} \mathrm{L}^{-1}, 6,45 \% \mathrm{cal}$ \\
\hline AA22N & Solo + biossólido tratado com ácido acético & $11.000 \mathrm{mg} \mathrm{L}^{-1}$ \\
\hline AA22C & Solo + biossólido tratado com ácido acético & $11.000 \mathrm{mg} \mathrm{L}^{-1}, 16,7 \% \mathrm{cal}$ \\
\hline HCS & Solo + biossólido tratado com hipoclorito de sódio & $2.500 \mathrm{mg} \mathrm{L}^{-1}$ \\
\hline $\mathrm{pH}$ & Solo + biossólido tratado com peróxido de hidrogênio & $300 \mathrm{mg} \mathrm{L}^{-1}$ \\
\hline
\end{tabular}


seca da parte aérea das plantas, indicativo do efeito nutricional proporcionado pela adição do biossólido no solo de cultivo, foi influenciada positivamente e seus valores aumentados com a aplicação do lodo (Figura 1A). Esses resultados estão de acordo com os obtidos por Konrad \& Castilhos (2002), Simonete et al. (2003) e Biondi \& Nascimento (2005), que observaram comportamento semelhante para a fitomassa das partes aéreas de plantas de milho, fertilizadas com lodo de esgoto.
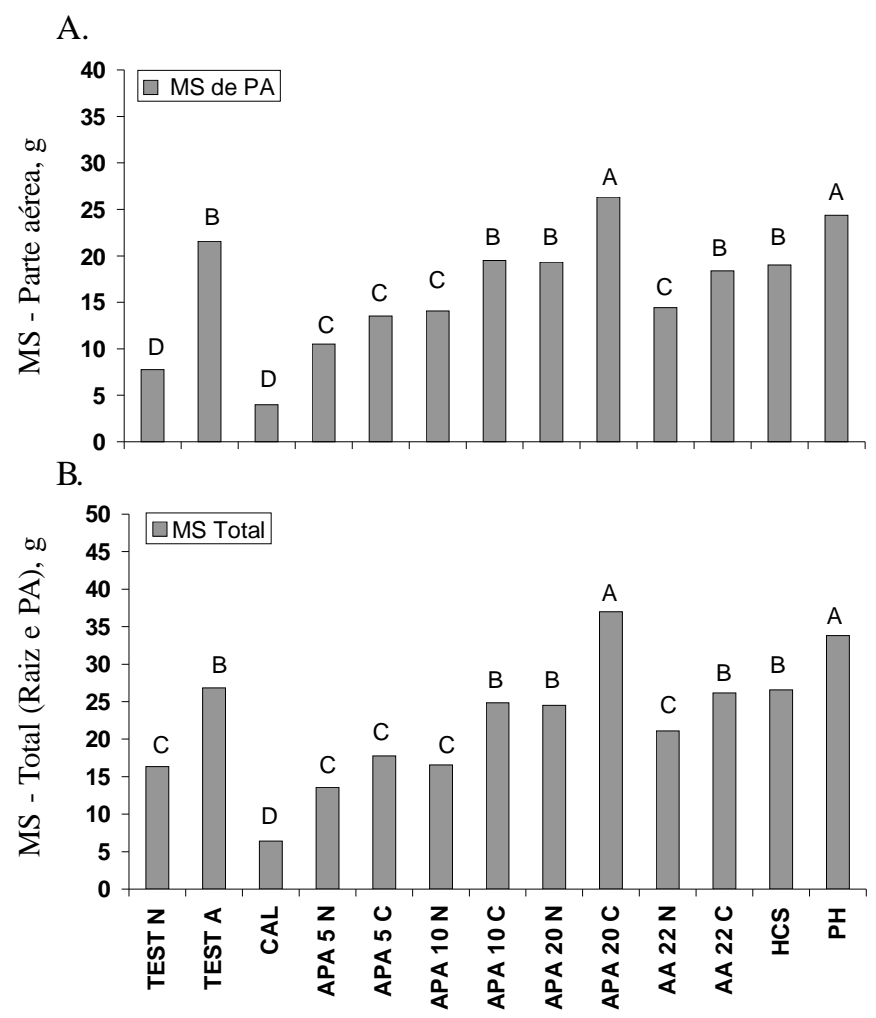

Figura 1. Produção de matéria seca (MS) da parte aérea (A) e total (B) do milho, com análise estatística dos dados, em classes de médias indicadas por letras ( $A, B, C$ ou $D$ )

A produção de matéria seca total (MST) no TEST-A foi superior ao TEST-N, mostrando que a adição do biossólido ao solo aumentou a produção de matéria seca. Os resultados obtidos concordam com Pedroza et al. (2003), Simonete et al. (2003), Tranin et al. (2005), Souto et al. (2005) e Araújo et al. (2009), que encontraram correlações positivas entre os aumentos nas doses de lodo e produção de matéria seca das plantas.

Barbosa et al. (2007a), observaram maior disponibilidade de nutrientes no solo, proporcionada pela aplicação do lodo de esgoto, o que ocasionou a vantagem de melhorar o crescimento de planta de milho safrinha, com maior produção de matéria seca e, consequentemente, aumento da produtividade.

Figueiredo et al. (2005), avaliando a cultura do algodão irrigado com água residuária e adubado com biossólido, obtiveram resposta positiva na influência da altura das plantas, enquanto Lemainski \& Silva (2006), utilizando lodo de esgoto, concluíram que o lodo foi mais eficiente na produção de grãos de milho, quando comparado com o fertilizante mineral.

Os menores valores de MSPA e MST foram constatados no tratamento CAL, sinalizando que a caleação, nas condições estudadas, isto é, dose de cal aplicada ao biossólido (30\% MS), determinando grande elevação de $\mathrm{pH}$, dose de biossólido adicionado ao solo $\left(50 \mathrm{t} \mathrm{ha}^{-1}\right)$, e plantio em vasos, resultou em efeito negativo no desenvolvimento das plantas, com o pior resultado para a produção de MS entre os tratamentos estudados (Figura 1A e 1B). O resultado é condizente com Barbosa et al. (2007b), ao relatarem aumento na produção de matéria seca de milho, em função da aplicação de lodo de esgoto, porém no tratamento com cal o resultado foi negativo.

A alta produção de MS pelo tratamento APA20C sugere que a adição de ácido peracético, mesmo na maior dosagem (920 mg L ${ }^{-1}$ ), não interferiu na disponibilidade dos nutrientes no lodo. Segundo Fraser et al. (1984), o tempo de contato do ácido com lodo é curto e os produtos da decomposição são biodegradáveis; assim, os ciclos geoquímicos essenciais executados pelos micro-organismos no solo, que incluem a mineralização de carbono orgânico, nitrogênio e enxofre, não são afetados.

\section{Concentrações de nutrientes na parte aérea}

Houve aumento nos teores de $\mathrm{N}$ em todos os tratamentos que receberam o lodo de esgoto (Figura 2A). O tratamento que não recebeu lodo mostrou sinais de deficiência de elemento, como pouco desenvolvimento da parte aérea e senescência precoce das folhas mais velhas. Gomes et al. (2007), avaliando a produtividade e composição mineral de plantas de milho em solo adubado com lodo de esgoto, observaram que um aumento das doses de lodo proporcionou incrementos nos teores de $\mathrm{N}$ nas folhas de milho e, segundo os autores, a aplicação do resíduo aumentou a absorção deste nutriente pelas plantas.

Para Lobo \& Grassi Filho (2007), o N proveniente da adubação mineral pode ser substituído pelo $\mathrm{N}$ proveniente do lodo de esgoto. Os autores relatam um aumento significativo na produtividade de grãos, rendimento de óleo e matéria seca em girassol com a utilização de lodo de esgoto como fonte de $\mathrm{N}$.

Berton et al. (1989), avaliando a aplicação do lodo de esgoto em cinco solos paulista, observaram elevação do $\mathrm{pH}$, redução do $\mathrm{Al}^{+3}$ tóxico, aumentos na absorção de nutrientes $\mathrm{N}, \mathrm{P}, \mathrm{K}, \mathrm{Ca}$, $\mathrm{Mg}$ e Zn e na produção de matéria seca, na cultura do milho; apesar disto, o tratamento CAL apresentou a menor concentração de $\mathrm{N}$ entre os tratamentos que receberam o lodo. Bonnet et al. (2002), avaliando o estado nutricional da parte aérea de mudas de $S$. terebinthifolius produzidas em substrato com lodo alcalinizado e compostado, apontou o fraco desempenho estatístico do lodo alcalinizado, que se manteve em classes isoladas, com as piores médias para $\mathrm{N}, \mathrm{K}, \mathrm{Al}, \mathrm{Fe}$, $\mathrm{Mn}$ e Cu.

Os teores de $\mathrm{P}$ apresentaram diferenças significativas entre tratamentos (Figura 2B). Segundo Moreira (2004), supõe-se que existam diferentes mecanismos que conferem maior aproveitamento do fósforo pela planta, muitos dos quais relacionados com o sistema radicular. De acordo com Marques et al. (2007), o fósforo, para ser absorvido, necessita estabelecer contato com as raízes, fenômeno este favorecido pelo deslocamento do elemento no solo, no processo de difusão; esses fatores são responsáveis pela recomendação de que este nutriente seja aplicado, de forma localizada, próximo ao sistema radicular das plantas. 

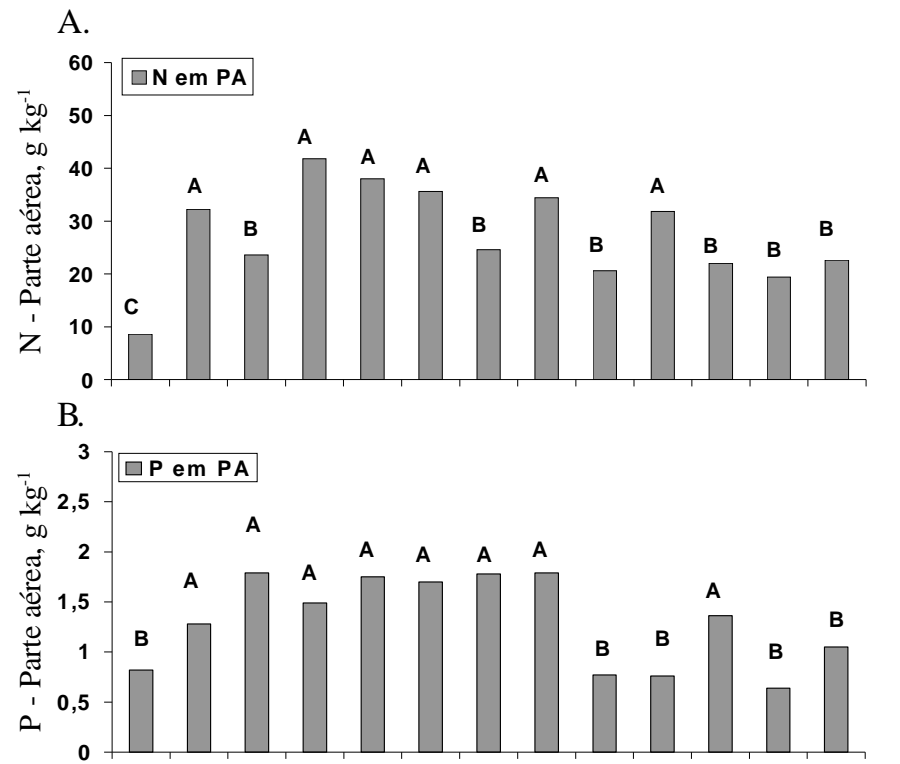

C.

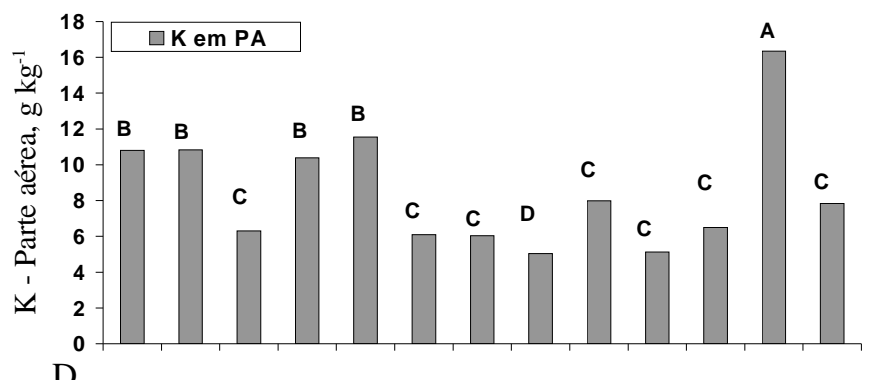

D.

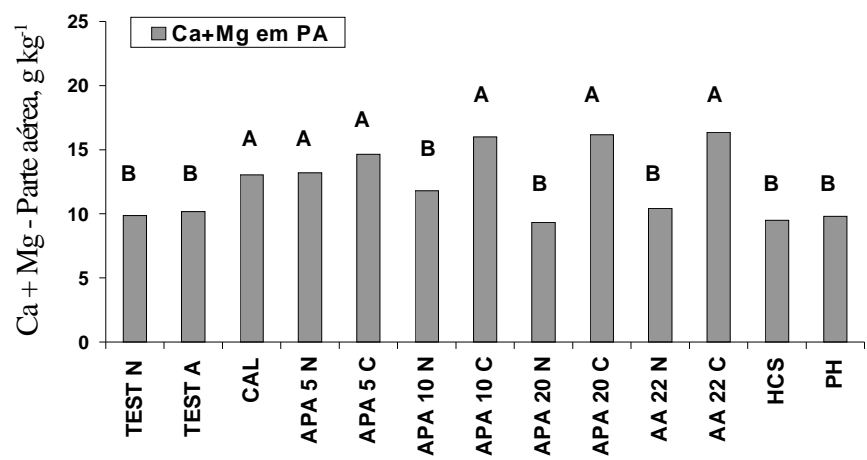

Figura 2. Teores de nitrogênio (A); fósforo $(B)$; potássio (C); cálcio+ magnésio (D), na parte aérea de milho cultivado em casa de vegetação, com análise estatística dos dados, em classes de médias indicadas por letras ( $A$, $B, C$ ou D)

A concentração de $\mathrm{Ca}+\mathrm{Mg}$ na parte aérea foi maior naqueles tratamentos que receberam cal em pequenas doses para neutralização, mostrando que houve translocação dos elementos para a parte aérea. De acordo com Gomes et al. (2007), o teor de cálcio na folha de milho aumentou linearmente em função das doses de lodo aplicadas. Este aumento no teor de $\mathrm{Ca}$ na folha se deve sobretudo ao alto teor deste elemento no resíduo, que corresponde a 2,2\% da matéria seca. Segundo Simonete et al. (2003), as quantidades de $\mathrm{Ca}$ e $\mathrm{Mg}$ acumuladas pelas plantas aumentaram significativamente com a aplicação das doses de lodo de esgoto.

Não houve diferença entre as quantidades absorvidas de $\mathrm{K}$ em função da aplicação de lodo de esgoto, fator concordante com as afirmações de Linden et al. (1983) e Barbosa et al. (2007a), os quais ressaltaram a baixa concentração no lodo em termos de potássio. De acordo com Gomes et al. (2007), aplicações de doses crescentes de lodo de esgoto a um Argissolo Amarelo, não alteraram as concentrações de K no tecido foliar de plantas de milho, porém se observou diferença significativa entre os tratamentos com os produtos químicos e o HCS apresentou a maior concentração de K; neste caso, o potássio pode ter sido liberado do lodo de esgoto devido ao tratamento com o hipoclorito, que ataca mais vigorosamente a matéria orgânica, decompondo-a.

Os teores médios de $\mathrm{Cu}$ encontrados na parte aérea das plantas dos tratamentos com e sem biossólido, se encontram dentro do intervalo considerado adequado de $6-20 \mathrm{mg} \mathrm{kg}^{-1}$, relatado por Malavolta et al. (1997) e Raij \& Cantarella (1996), mesmo que apenas dois tratamentos, APA5N e APA20N, tenham ultrapassado o limite de $20 \mathrm{mg} \mathrm{kg}^{-1}$, porém não houve sintomas de fitotoxidez (Figura 3A).

Não foi observada diferença significativa nos teores de $\mathrm{Cu}$ em função da aplicação do lodo, o que corrobora com Gomes et al. (2006), que não verificaram alterações nos teores de $\mathrm{Cu}$ em plantas de milho, em função da aplicação de doses crescentes de lodo de esgoto. Também Martins et al. (2003) relataram que o $\mathrm{Cu}$ foi o elemento menos afetado em plantas de milho, pela adição, ao solo, de lodo de esgoto com e sem calcário.

Nogueira et al. (2007), avaliando metais potencialmente tóxicos e patógenos em milho e feijão caupi consorciados, adubados com lodo de esgoto, não detectaram teores de $\mathrm{Cu}$ nos grãos de milho nem de feijão caupi; entretanto, Anjos \& Mattiazzo (2000), estudando metais potencialmente tóxicos em plantas de milho cultivadas em latossolos repetidamente tratados com biossólido, verificaram que as plantas que se desenvolveram nos tratamentos com biossólido, apresentaram maiores teores de $\mathrm{Cu}$, em todas as partes analisadas, em comparação com a testemunha.

Não ocorreu diferença estatística nos teores de Fe entre os tratamentos propostos (Figura 3B); este resultado indica que a maior parte do Fe presente no lodo se encontra em forma de baixa disponibilidade, tal como sugerido por Martins et al. (2003). Outro fator a ser consideradoé o baixo teor de ferro em Latossolos Vermelho Distróficos, visto que os teores totais se concentram, preferivelmente, na fração argila na forma de óxidos de ferro, como a hematita. Os teores de ferro total (Fet) e livre (Fed) são muito próximos, pois as frações silte e areia praticamente não possuem minerais com ferro em sua constituição.

Gomes et al. (2007), no entanto, mencionaram aumentos significativos na concentração de Fe nas folhas de milho, em função de doses de lodo de esgoto aplicadas em Argissolo Amarelo. Resultado semelhante foi encontrado por Silva et al. (2002), que obtiveram aumentos no teor de Fe com a aplicação de doses crescentes de lodo de esgoto.

Os teores de $\mathrm{Mn}$ indicaram diferenças entre os tratamentos, sendo que nos tratamentos APA20N e APA20C observou-se maior concentração do elemento, com teores médios de 564,7 e $594,3 \mathrm{mg} \mathrm{kg}^{-1}$, respectivamente, apesar dos valores estarem acima de $200 \mathrm{mg} \mathrm{kg}^{-1}$, nível considerado tolerável para a cultura 
A.

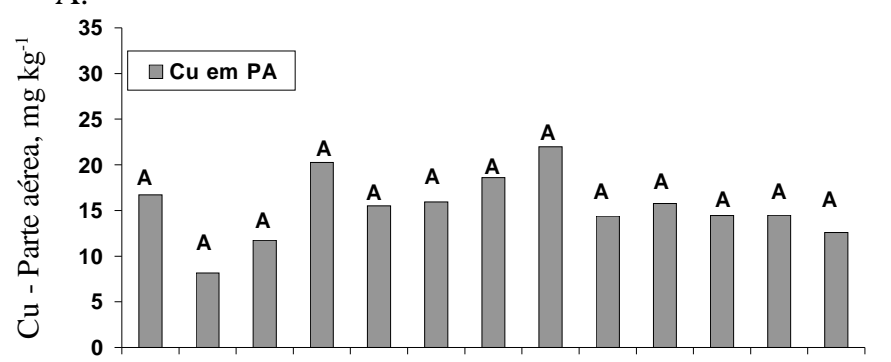

C.
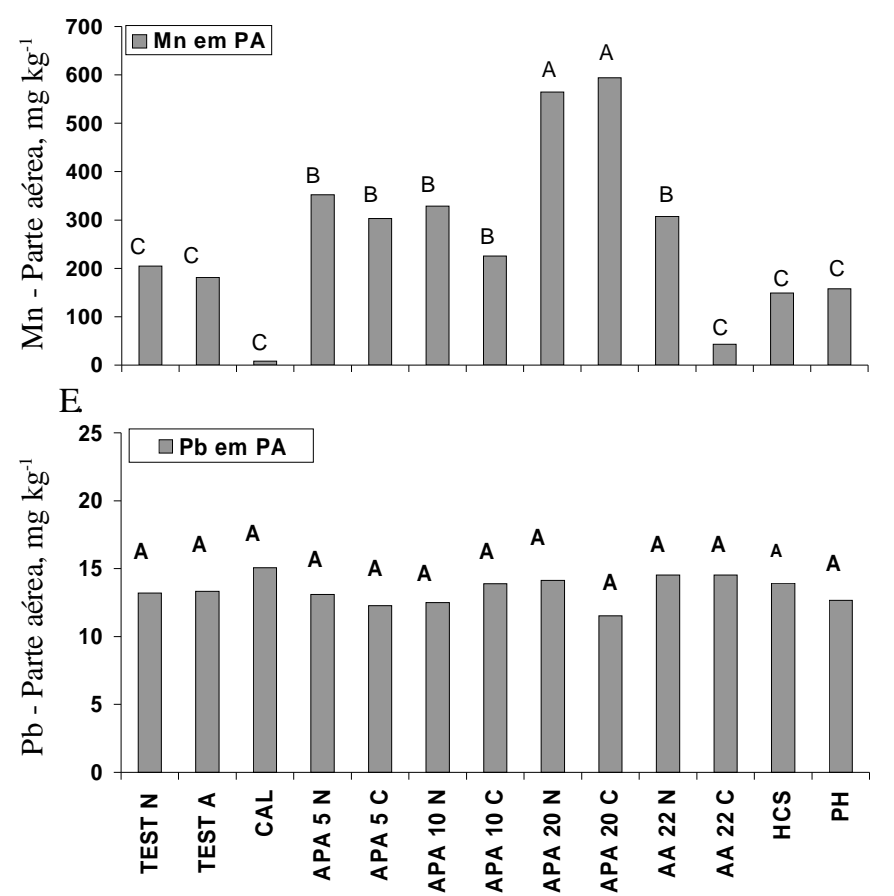

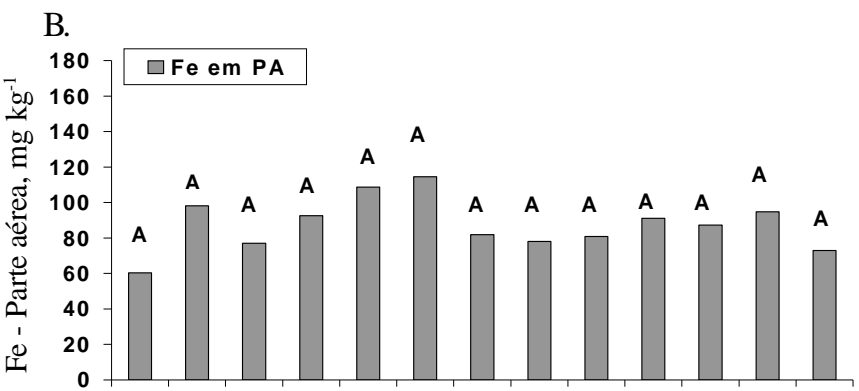

D.

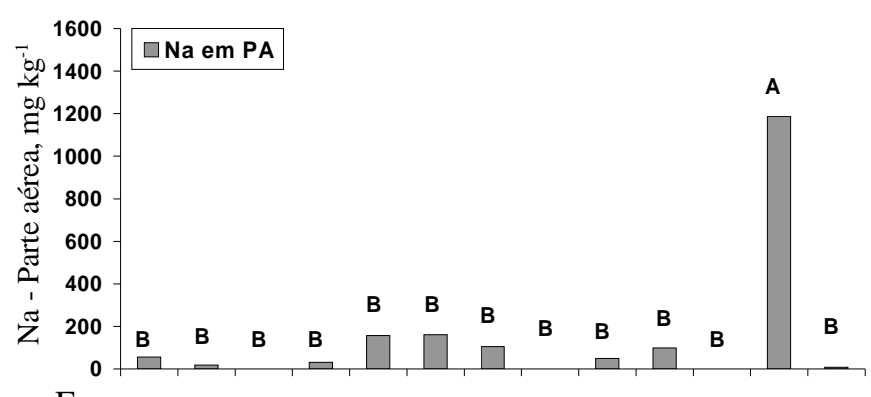

$\mathrm{F}$

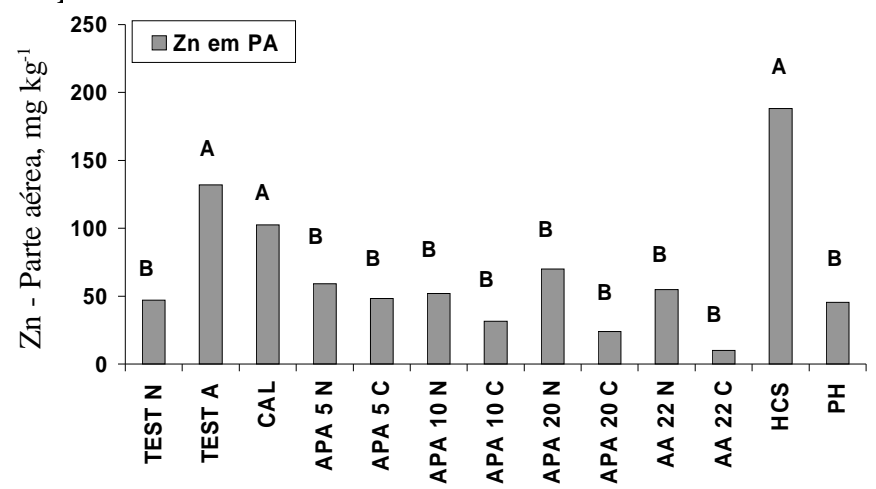

Figura 3. Teor de cobre (A); ferro (B); manganês (C); sódio (D); chumbo (E) e zinco (F), na parte aérea de milho cultivado em casa de vegetação, com análise estatística dos dados, em classes de médias indicadas por letras (A, B ou C)

de milho; segundo Raij et al. (1996), não se verificaram sintomas de fitotoxidez, sugerindo que a condição redox do experimento não apresentou as condições redutoras necessárias para a presença de Mn tóxico, isto é, o método Mehlich-1 extraiu uma grande quantidade de Mn mas, devido à presença de condições oxídicas do meio e a presença de grande quantidade de matéria orgânica, não determinaram sintomas de fitotoxidez nas plantas.

Os tratamentos AA22C e CAL apresentaram as menores concentrações do elemento. Faixas mais elevadas de $\mathrm{pH}$ interferem na disponibilidade de Mn (Andreoli, 1999). Na prática, a calagem eleva o $\mathrm{pH}$ e precipita o excesso de Mn disponível, reduzindo sua absorção pela planta (Kupper et al., 1968).

Observou-se que o tratamento APA20C, que mais produziu matéria seca, apresentou também alto teor de Mn na parte aérea (Figura 3C). Malavolta et al. (1997), observaram que o aumento da fotossíntese está diretamente relacionado com a concentração de manganês na planta e na sua carência a produção pode ser significativamente afetada. De acordo com Rangel et al. (2006), os teores de Mn em folhas e grãos de milho aumentaram progressivamente com o incremento das doses de lodo, em dois cultivos avaliados.
Os teores de Na no tratamento HCS foram significantemente altos e tiveram, como procedência, o íon sódio presente no hipoclorito de sódio utilizado na higienização do lodo (Figura 3D).

Os teores de $\mathrm{Zn}$ nas folhas de milho aumentaram de modo significativo, como resposta à aplicação do lodo de esgoto (Figura 3E), o que corrobora com os resultados obtidos por Bidwell \& Dowdy (1987), Martins et al. (2003), Oliveira et al. (2005), Rangel et al. (2006) e Nogueira et al. (2008).

Verificou-se que, apesar da aplicação de Zn via biossólido em alguns tratamentos exceder o limite de intervalo de 5-100 $\mathrm{mg} \mathrm{kg}^{-1}$, considerado adequado por Raij \& Cantarella (1996), não se observou fitotoxicidade deste elemento nas plantas de milho. Segundo Chang et al. (1987), as quantidades de metais absorvidas pelas plantas em áreas que receberam lodo de esgoto, são pequenas e geralmente inferiores a $1 \%$ da quantidade fornecida pelo resíduo.

Os teores de $\mathrm{Pb}$ não apresentaram diferença significativa entre os tratamentos (Figura 3E). Segundo Kabata-Pendias \& Pendias (2000), o Pb pode ser considerado um dos metais potencialmente tóxicos menos móveis no solo, o que pode torná-lo menos disponível às plantas. Como se dá com a maioria 
dos metais potencialmente tóxicos, atributos químicos do solo, como pH, CTC (capacidade de troca de cátions), MO, além dos atributos físicos e mineralógicos do solo parecem ter contribuído decididamente para a dinâmica dos metais no solo.

Segundo Nogueira et al. (2008), a forte retenção do Pb no solo controla sua disponibilidade. Para Malavolta (2006), o Pb se acumula nas paredes da célula das raízes e, em certas condições, se formam precipitados amorfos identificados como fosfato de chumbo, no caso do milho. Berton et al. (1989) relatam que, dentro da planta, alguns metais se concentram nas raízes, não sendo então transportados para a parte aérea.

Melo et al. (2001), afirmam que a elevação de $\mathrm{pH}$ do solo promove precipitação de metais pesados na forma de hidróxidos, fosfatos e carbonatos, e de complexos insolúveis, com a matéria orgânica.

Com relação à possibilidade de incrementos na absorção de $\mathrm{Cd}, \mathrm{Cr}$ e Ni pelas plantas de milho, não foram tecidas maiores considerações, tendo em vista que suas concentrações nas amostras analisadas estiveram abaixo do limite de determinação do método analítico utilizado, resultado que corrobora com Oliveira \& Mattiazzo (2001).

\section{Conclusões}

1. A adição do biossólido ao solo aumentou os teores dos macronutrientes na parte aérea das plantas e promoveu aumento na quantidade de matéria seca nas plantas de milho.

2. Os teores de elementos traço estiveram abaixo dos limites fitotóxicos e as plantas não apresentaram sintomas de deficiência ou toxidez.

3. A caleação a $30 \%$ MS apresentou forte alcalinidade e diminuiu os teores de nutrientes do biossólido.

4. Os ácidos orgânicos não interferiram na disponibilidade de nutrientes do lodo e, mesmo quando aplicados ao solo, sem a neutralização, proporcionaram apenas leve acidificação do solo.

5. O ácido peracético (APA) apresentou o melhor efeito de redução de patógenos, entre os tratamentos alternativos, e no tratamento APA20C observou-se um efeito conjugado do ácido peracético com a cal, que determinou a maior produção de matéria seca.

\section{LITERATURA CITADA}

Andreoli, C. V. Uso e manejo do lodo de esgoto na agricultura e sua influência em características ambientais no agrossistema. Curitiba: UFPR, 1999. Tese Doutorado

Andreoli, C. V.; Lara, A. I.; Fernandes, F. Reciclagem de biossólidos: Transformando problemas em soluções. 2.ed. Curitiba: SANEPAR, FINEP, 2001a.

Andreoli, C. V.; von Sperling, M.; Fernandes, F. Lodo de esgotos: Tratamento e disposição final. v.6. Belo Horizonte: UFMG/SANEPAR, 2001b.

Anjos, A. R. M.; Mattiazzo, M. E. Metais pesados em plantas de milho cultivadas em latossolos repetidamente tratados com biossólido. Scientia Agricola, v.57, p.769-776, 2000.
Araújo, F. F.; Gil, F. C.; Tiritan, C. S. Lodo de esgoto na fertilidade do solo, na nutrição de Brachiaria decumbens e na atividade da desidrogenase. Pesquisa Agropecuária Tropical, v.39, p.1-6, 2009.

Barbosa, G. M. C.; Tavares Filho, J.; Brito, O. R.; Fonseca, I. C. B. Efeito residual do lodo de esgoto na produtividade do milho safrinha. Revista Brasileira de Ciência do Solo, v.31, p.601-605, 2007a.

Barbosa, G. M. C.; Tavares Filho, J.; Brito, O. R.; Fonseca, I. C. B. Equilíbrio de bases no solo e produção de matéria seca de milho (Zea mays L.) em solos tratados com lodo de esgoto, carbonato de cálcio e cal virgem. Acta Scientiarum Agronomia, v.29, p.709-714, 2007b.

Barrios, J. A.; Jimenez, B.; Maya, C. Tratamiento ácido de lodos residuales fisicoquímicos para reducir el contenido de microorganismos. Congreso Interamericano de Ingeniería Sanitaria y Ambiental, 28., 2002, Cancún. Anais... Cancún: AIDIS, 2002. CD Rom.

Barros, I. T.; Costa, A. C. S.; Andreoli. C. V.; Avaliação da higienização do lodo de esgoto anaeróbio através do tratamento ácido e alcalino. Sanare, v.24, p.61-69, 2006.

Berton, R. S.; Camargo, O. A.; Valadares, J. M. A. S. Absorção de nutrientes pelo milho em resposta à adição de lodo de esgoto a cinco solos paulistas. Revista Brasileira de Ciência do Solo, v.13, p.187-192, 1989.

Biondi, C. M.; Nascimento, C. W. A. Acúmulo de nitrogênio e produção de matéria seca de plantas em solos tratados com lodo de esgoto. Caatinga, v.18, p.123-128, 2005.

Bidwell, A. M.; Dowdy, R. H. Cadmium and zinc availability to corn following termination of sewage sludge applications. Journal Environmental Quality, v.16, p.438-442, 1987.

Bonnet, B. R. P.; Wisniewski, C.; Reissmann, C. B.; Nogueira, A. C.; Andreoli, C. V., Barbieri, S. J. Effects of substrates composed of biosolids on the production of Eucalyptus viminalis, Schinus terebinthifolius and Mimosa scabrella seedlings and on the nutritional status of Schinus terebinthifolius seedlings. Water Science \& Technology, v.46, p.239-246, 2002.

Chang, A. C.; Hinesly, T. D.; Bates, T. E.; Doner, H. E.; Dowdy, R. H.; Ryan, J. A. Effects of long-term sludge application on accumulation of trace elements by crops. In: Page, A. L.; Logan, T. G.; Ryan, J. A. Land application of sludge. Chelsea: Lewis Publishers, 1987. cap.4, p.53-66.

EMBRAPA - Empresa Brasileira de Pesquisa Agropecuária. Sistema brasileiro de classificação de solos. Centro Nacional de Pesquisa de Solos. Rio de Janeiro: Embrapa CNPS, 2006. $306 \mathrm{p}$.

Figueiredo, I. C. M.; Lima, V. L. A. de; Beltrão, N. E. de M.; Araújo, M. G. F.; Santos, T. S; Azevedo, C. A. V. de. Uso da água residuária tratada e do biossólido no algodão colorido: Produção e seus componentes. Revista Brasileira de Engenharia Agrícola e Ambiental, v.9, p.288-291, 2005.

Fraser, J. A. L.; Godfree, A. F.; Jones, F. Use of peracetic acid in operational sewage sludge disposal to pasture. Water, Science and Technology, v.17, p.451-466, 1984.

Gomes, S. B. V.; Nascimento, C. W. A.; Biondi, C. M. Produtividade e composição mineral de plantas de milho em solo adubado com lodo de esgoto. Revista Brasileira de Engenharia Agrícola e Ambiental, v.11, p.459-465, 2007. 
Gomes, S. B. V.; Nascimento, C. W. A.; Biondi, C. M.; Accioly, A. M. A. Distribuição de metais pesados em plantas de milho cultivadas em Argissolo tratado com lodo de esgoto. Ciência Rural, v.36, p.1689-1695, 2006.

González, A., Rodríguez, A., Barrios, J. A., Maya, C., Jiménez, B. Evaluación del tratamiento de lodo fisicoquímico con ácidos acético y peracético para producir biosólidos. In: Congreso Nacional Femisca, 8, 2002, Tomo I, Anais... 2002. p.251-255.

Rao, K. J.; Shantaram, M.V. Effect of urban solid wastes on cadmium, lead and zinc in contaminated soils from southwest Poland. Journal Environmental Biology, v.17, p.25-32, 1996.

Kabata-Pendias, A.; Pendias, H. Trace elements in soils and plants. 3.ed. Boca Raton: CRC Press, 2000. 331p.

Konrad, E. E.; Castilhos, D. D. Alterações químicas do solo e crescimento do milho decorrentes da adição de lodos de curtume. Revista Brasileira de Ciência de Solo, v.26, p.257-265, 2002.

Kupper, A; Sacchetto, M. T. D.; van Raij, B. Formas e níveis de manganês em alguns solos com e sem calagem. Bragantia, v.27, p.15-17, 1968.

Lemainski, J.; Silva, J. E. Utilização do biossólido da CAESB na produção de milho no Distrito Federal. Revista Brasileira de Ciência do Solo, v.30, p.741-750, 2006.

Linden, D. R.; Clapp, C. E.; Dowdoy, R. H. Hydrologic management: Nutrients. In: Page, A. L.; Geason, T. L.; Smith, I. E.; Iskandar, J. K.; Summers, L. E. (ed.). Utilization of municipal wastewater and sludge on land. Riverside: University of California, 1983. p.79-103.

Lobo, F. T.; Grassi Filho, H. Níveis de lodo de esgoto na produtividade do girassol. Revista de la Ciencia del Suelo Nutrición Vegetal, v.7, p.16-25. 2007.

Lopes, J. C.; Ribeiro, L. G.; Araújo, M. G.; Beraldo, M. R. B. S. Produção de alface com doses de lodo de esgoto. Horticultura Brasileira, v.23, p.143-147, 2005.

Malavolta, E. Elementos benéficos e tóxicos. In: Malavolta, E. Manual de nutrição mineral de plantas. São Paulo: Agronômica Ceres, 2006. p.418-511.

Malavolta, E.; Vitti, G. C.; Oliveira, S. A. Avaliação do estado nutricional das plantas: princípios e aplicações. Piracicaba: Potafós, 1997. 319p.

Marques, M. O.; Bellingieri, P. A.; Marques, T. A.; Nogueira, T. A. R. Qualidade e produtividade da cana-de-açúcar cultivada em solo com doses crescentes de lodo de esgoto. Bioscience Journal, v.23, p.111-122, 2007.

Martins A. L. C.; Bataglia O. C.; CamargoO. A.; Cantarella,H. Produção de grãos e absorção de $\mathrm{Cu}, \mathrm{Fe}$, Mn e Zn pelo milho em solo adubado com lodo de esgoto, com e sem calcário. Revista Brasileira de Ciência de Solo, v.27, p.563-574, 2003.

Melo, W. J.; Marques, M. O.; Melo, V. P. O uso agrícola do biossólido e as propriedades do solo. In: Tsutiya, M. T.; Comparini, J. B.; Além Sobrinho, P.; Hespanhol, I.; Carvalho, P. C. T.; Melfi, A. J.; Melo, W. J.; Marques, M. O. (ed.). Biossólidos na agricultura. São Paulo: SABESP, 2001.p.289-363.

Moreira, M. F. Desenvolvimento do sistema radicular e da parte aérea do feijoeiro comum em função da distribuição e do teor de fósforo no solo. Piracicaba: ESALQ/USP, 2004. 135p. Tese Doutorado
Nascimento, C. W. A.; Barros, D. A. S.; Melo, E. E. C.; Oliveira, A. B. Alterações químicas em solos e crescimento de milho e feijoeiro após aplicação de lodo de esgoto. Revista Brasileira de Ciência do Solo, v.28, p.385-392, 2004.

Nogueira, T. A. R.; Oliveira, L. R.; Melo, W. J.; Fonseca, I. M.; Melo, G. M. P.; Melo, V. P.; Marques, M. O. Cádmio, cromo, chumbo e zinco em plantas de milho e em Latossolo após nove aplicações anuais de lodo de esgoto. Revista Brasileira de Ciência do Solo, v.32, p.2195-2207, 2008.

Nogueira, T. A. R.; Sampaio, R. A.; Fonseca, I. M.; Ferreira, C. S.; Santos, S. E.; Ferreira, L. C.; Gomes, E.; Fernandes, L. A. Metais pesados e patógenos em milho e feijão caupi consorciados, adubados com lodo de esgoto. Revista Brasileira de Engenharia Agrícola e Ambiental, v.11, p.331338, 2007.

Oliveira, F. C.; Mattiazzo, M. E. Metais pesados em Latossolo tratado com lodo de esgoto e em plantas de cana-de-açúcar. Scientia Agricola, v.58, p.581-593, 2001.

Oliveira, K. W.; Melo, W. J.; Pereira, G. T.; Melo, V. P., Melo, G. P. Heavy metals in oxisols amended with biosolids and cropped with maize in a long-term experiment. Scientia Agricola, v.62, p.381-388, 2005.

Pedroza, J. P.; van Haandel, A.C.; Beltrão, N. E. M.; Dionísio, J. A. Produção e componentes do algodoeiro herbáceo em função da aplicação de biossólidos. Revista Brasileira de Engenharia Agrícola e Ambiental, v.7, p.483-488, 2003.

Pedroza, J. P.; van Haandel, A. C.; Beltrão, N. E. de M.; Dionísio, J. A.; Duarte, M. E. M. Qualidade tecnológica da pluma do algodoeiro herbáceo cultivado com biossólidos. Revista Brasileira Engenharia Agrícola Ambiental, v.10, p.586-592, 2006.

Rangel, O. J. P.; Silva, C. A.; Bettiol, W.; Dynia, J. F. Efeito de aplicações de lodo de esgoto sobre os teores de metais pesados em folhas e grãos de milho. Revista Brasileira de Ciência do Solo, v.30, p.583-594, 2006.

Rocha, M. T.; Shirota, R. Disposição final de lodo de esgoto. Revista de Estudos Ambientais, v.1, p.1-25, 1999.

Ros, C. O.; Aita, C.; Cerettam, C. A.; Fries, M. R. Lodo de esgoto: Efeito imediato no milheto e residual na associação aveiaervilhaca. Revista Brasileira de Ciência do Solo, v.17, p.257261, 1991.

Sánchez-Ruiz, C.; Martínez-Royano, S.; Tejero-Monzón, I. An evaluation of the efficiency and impact of raw wasterwater disinfection with peracetic acid prior to ocean discharge. Water, Science and Technology, v.32, p.159-166, 1995.

Scott, A. J.; Knott, M. A cluster analysis method for grouping means in the analysis of variance. Biometrics, v.30, p.507$512,1974$.

Silva, J. E.; Resck, D. V. S.; Sharma, R. D. Alternativa agronômica para o biossólido produzido no Distrito Federal: I. Efeito na produção de milho e na adição de metais pesados em Latossolo no Cerrado. Revista Brasileira de Ciência do Solo, v.26, p.487-495, 2002.

Simonete, M. A.; Kiehl, J. C.; Andrade, C. A.; Teixeira, C. F. A. Efeito do lodo de esgoto em um Argissolo e no crescimento e nutrição de milho. Pesquisa Agropecuária Brasileira, v.38, p.1187-1195, 2003. 
Soares, F.; Amaral Sobrinho, N. M. B.; Mazur, N. Influência de diferentes manejos agrícolas na distribuição de metais pesados no solo e em plantas de tomate. Revista Brasileira de Ciência do Solo, v.26, p.535-542, 2002.

Souto, L. S.; Silva, L. M.; Lobo, T. F.; Fernandes, D. M.; Lacerda, N. B. Níveis e formas de aplicação de lodo de esgoto na nutrição e crescimento inicial da mamoneira. Revista Brasileira de Engenharia Agrícola e Ambiental, v.9, p.274-277, 2005.

Thomaz-Soccol, V.; Paulino, R. C.; Castro, E. A. Metodologia de análise parasitológica em lodo de esgoto e esgoto In: Andreoli, C. V.; Bonnet, B. R. P. (org.) Manual de métodos para análises microbiológicas e parasitológicas em reciclagem agrícola de lodo de esgoto. Curitiba: SANEPAR/ PROSAB, 1998. cap.3, p. 27-34.
Tranin, I. C. B.; Siqueira, J. O.; Moreira, F. M. S. Avaliação agronômica de um biossólido industrial para a cultura do milho. Pesquisa Agropecuária Brasileira, v.40, p.261-269, 2005.

Valsecchi, G; Giglioti, C.; Farini, A. Microbial biomass, activity, and organic matter accumulation in soils contaminated with heavy metals. Biology and Fertility of Soils, v.20, p.253-259, 1995.

van Raij, B.; Cantarella, H. Milho para grãos e silagem. In: van Raij, B.; Cantarella, H.; Quaggio, J. A.; Furlani, A. M. C. (ed.) Recomendações de adubação e calagem para o estado de São Paulo. 2.ed. Campinas: Instituto Agronômico, 1996. p.5659. Boletim Técnico, 100

Vieira, R. F.; Cardoso, A. A. Variações nos teores de nitrogênio mineral em solo suplementado com lodo de esgoto. Pesquisa Agropecuária Brasileira, v.38, p.867- 874, 2003. 